\title{
Nonveridical heart rate feedback and emotional attribution
}

\author{
DAVID YOUNG \\ Miami Valley Hospital, Dayton, Ohio 45409 \\ RICHARD HIRSCHMAN \\ Kent State University, Kent, Ohio 44242 \\ and \\ MICHAEL CLARK \\ Veterans Administration Medical Center, Chillicothe, Ohio 45601
}

\begin{abstract}
The purpose of this study was to examine the effects of nonveridical heart rate feedback on perceived affect and actual heart rate change. Dentally anxious subjects were presented with either increasing or decreasing nonveridical heart rate feedback while they were viewing a videotape of a provocative dental procedure. Dentally anxious males in the decrease condition responded to the dental procedure with less unpleasantness than did dentally anxious males in the increase condition. No comparable effect was found for females. In addition, subjects in the decrease condition demonstrated a small decrease in actual heart rate across dental segments, whereas subjects in the increase condition demonstrated a small increase in actual heart rate across dental segments. These findings are discussed in terms of a cognitive appraisal theory of emotion and a mechanism that may account for the effects of veridical feedback on perceived affect.
\end{abstract}

The contention that physiological activity is an important mediator of emotional attributions is supported by studies in which emotional attributions covaried with voluntarily induced changes in heart rate. For example, voluntary heart rate slowing resulted in larger decreases in the perceived aversiveness of shocks for subjects who typically were aware of their cardiovascular reactions than for subjects who typically were unaware of their cardiovascular reactions (Sirota, Schwartz, \& Shapiro, 1974, 1976). Also, speech-anxious subjects were able to reduce their anxiety during speech presentations by voluntarily decreasing their heart rate (Gatchel \& Proctor, 1976). Similarly, high dentally anxious subjects were able to reduce their discomfort to the videotaped presentation of a dental procedure by voluntarily decreasing their heart rate (Oliver \& Hirschman, 1982).

The specific mechanism that might account for these findings is unclear. Presumably, transient changes in heart rate may exert a direct interoceptive influence on inhibitory and excitatory central nervous system pathways (Lacey \& Lacey, 1978). It also is possible that the amplified heart rate signal could be used exteroceptively to appraise affective state (Hirschman, Young, \& Nelson, 1979 ) or could be used to appraise expectancies about

This investigation was supported in part by NIDR Grant DE 06294, awarded to the second author. Requests for reprints should be sent to Richard Hirschman, Department of Psychology, Kent State University, Kent, Ohio 44242. the effects of the feedback manipulation (Kazdin \& Wilcoxin, 1976).

There is yet another possible mechanism that might account for the effects of voluntary heart rate control on highly anxious subjects and cardiac-aware subjects. Anxiety often occurs in individuals who exaggerate internal and external cues (Goldstein \& Palmer, 1975). Thus, for anxious subjects, the cognitive interpretation of their physiological reactions may be a more important determinant of their affect than are their actual physiological reactions. This notion is supported by the results from studies in which nonveridical autonomic feedback was used (Hirschman, 1975; Hirschman \& Hawk, 1978; Hirschman \& Clark, in press; Valins, 1967). ${ }^{1}$ For example, Valins (1967) discovered that subjects who were classified as emotional rated the attractiveness of slides of female nudes as a function of the rate of accompanying nonveridical heart rate feedback. In contrast, unemotional subjects made less use of the feedback when evaluating the slides. Unfortunately, in the Valins study, there was no mention of the effects of nonveridical feedback on actual heart rate.

With these considerations in mind, the purpose of this study was to examine the effects of the perception of heart rate change, via nonveridical feedback, on perceived affect and actual heart rate. It was expected that the effects of nonveridical heart rate feedback on a situationally defined high-anxious population would parallel the previously reported effects of veridical 
heart rate feedback. Increasing and decreasing nonveridical feedback conditions were used in this study so as to approximate the conditions that were used in several previous studies of veridical feedback (Sirota et al., 1974, 1976). In addition, a dental format was used for the following reasons: (1) Veridical heart rate feedback has been shown to alter dental discomfort in high dentally anxious subjects (Oliver \& Hirschman, 1982). (2) High dentally anxious subjects have higher heart rates during dental treatment than do low dentally anxious subjects (Corah, Gale, \& Illig, 1979).

It was expected that dentally anxious subjects who were exposed to decreasing nonveridical heart rate feedback would experience less discomfort and show lower heart rates to the videotaped presentation of a firstperson dental procedure than would dentally anxious subjects who were exposed to increasing nonveridical heart rate feedback. Also, although little is known about the interactive effects of sex and nonveridical heart rate feedback, males and females are capable of voluntary heart rate control. Thus, both sexes were expected to be equally affected by the nonveridical feedback manipulation.

\section{METHOD}

\section{Subjects}

The subjects were 12 male and 12 female undergraduate students enrolled in an introductory psychology course. Participation in this experiment partially fulfilled a course requirement. They were preselected by having scores in the upper one-third of the distribution of scores on the Corah Dental Anxiety Scale (Corah, 1969). This scale is a relatively reliable and valid indicator of individual differences in anxiety associated with the anticipation and experience of dental treatment (Corah, Gale, \& Illig, 1978). The range of scores obtained from approximately 600 subjects was $4-19$ with a mean of 8.2 . The range of scores for the 24 subjects used in this study was 10-19. Each subject was randomly assigned to either the heart increase condition or the heart decrease condition such that there were six males and six females in each condition.

\section{Apparatus}

The dental stimulus was a videotape of a Class I amalgam restoration. It consists of nine 60 -sec segments (e.g., anesthetic injection and high-speed drilling). The videotape was produced by positioning the camera in the headrest of a dental chair. A realistic first-person effect was created by directing the dental procedures into the lens of the camera. This tape produced more stress in high dentally anxious subjects than in low dentally anxious subjects (Hirschman, Revland, Hawk, \& Young, 1980).

The dental videotape was accompanied by a series of prerecorded beeps that subjects heard via a speaker located in the subjects' room. For all subjects, the beeps varied in rate between 68 and 72 per minute during an initial 5-min adaptation period. With the onset of the dental videotape, subjects in the heart increase condition heard the rate increase from 72 to 80 to 90 to $100 \mathrm{beeps} / \mathrm{min}$, with the steps of the increase occurring at 3 -sec intervals. After attaining the $100-\mathrm{beep} / \mathrm{min}$ level, the rate varied between 95 and 105. During the last $10 \mathrm{sec}$ of each of the nine tape segments, the beep frequency decreased in 3-sec steps from 90 to 80 to 72 beeps $/ \mathrm{min}$. This pattern was repeated with each dental segment. Subjects in the heart decrease condition heard the beep rate decrease from 72 to 60 to 50 to 40 per minute, with the steps of the decrease again occurring at 3-sec intervals. After attaining the $40-\mathrm{beep} / \mathrm{min}$ level, the rate varied between 35 and 45 . During the last $10 \mathrm{sec}$ of each tape segment, the beep frequency increased in 3-sec steps from 50 to 60 to 72 beeps $/ \mathrm{min}$. As with the heart increase pattern, the heart decrease pattern was repeated for each dental segment. Also, it should be noted that the aforementioned rates were chosen because in pilot studies, these changes in rate were noticeable.

Heart rate responses were recorded on a Beckman Type RM polygraph using Beckman silver/silver-chloride electrodes attached to the right wrist and lower leg above the ankle. A BRS/LVE solid state logic system was used to coordinate the timing of the heart rate recording with the presentation of the prerecorded auditory beeps and the dental videotape.

\section{Procedure}

Upon arriving at the laboratory, subjects were assigned to either the heart increase condition or the heart decrease condition. The electrodes then were attached, at which point subjects were told that their heart rate would be "picked up" by an amplifier located next to them and then sent to an adjoining room for analysis. A 5-min adaptation period followed. Subsequently, all subjects were told that they would be viewing a dental procedure and that they should imagine that the procedure was actually being performed on them. They also were informed that at periodic intervals throughout the tape (after each segment), they would be asked to rate their feelings on a 15 -point scale in response to the previous dental segment. A rating of 1 represented extreme unpleasantness, and a rating of 15 represented extreme pleasantness.

At the end of the experiment, all subjects were asked to offer their impressions of the auditory stimuli relative to their discomfort during the dental presentation. Although the request was open-ended, it was relatively easy to determine if subjects were skeptical about the feedback manipulation. As a result of these interviews, two subjects were not included in the analyses. They were replaced by two additional subjects.

\section{RESULTS}

Analyses of variance were performed on the verbal reports of affect and on the mean heart rate change per dental segment. In each analysis, the between-subjects factors were conditions (heart increase and heart decrease) and sex (male and female) and the within-subjects factor was dental segments (one through nine). An analysis of the verbal report data revealed significant main effects for conditions $[F(1,20)=10.65, \mathrm{p}<.01]$ and for segments $[F(8,160)=29.29, p<.0001]$ and a significant interaction for Sex by Segments $[F(8,160)=2.09$, $\mathrm{p}<.05$ ]. Although it was not significant, there was a tendency for the feedback conditions to interact with $\operatorname{sex}[F(1,20)=2.24, p<.10]$. The significant main effects were accounted for by the following: Subjects in the heart decrease condition $($ mean $=6.3$ ) reported less unpleasantness in response to the dental presentation than did subjects in the heart increase condition $($ mean $=5.1)$. The segments effect reflected the fact that all subjects experienced the provocative segments (e.g., injection and drilling) as being more unpleasant than the earlier, more innocuous segments (e.g., the dentist examining $\mathrm{x}$-rays and then performing an oral examination). With respect to the Sex by Segments interaction, 
subsequent analyses were not performed because the groups as defined by sex were collapsed over conditions (heart increase and heart decrease) and, therefore, the results would have been uninterpretable. However, subsequent Newman-Keuls analyses of the Conditions by Sex interaction ${ }^{2}$ revealed that males in the heart decrease condition (mean $=6.6$ ) reported lower levels of unpleasantness than did males in the heart increase condition $($ mean $=4.8, p<.01)$. This difference was not significant for females.

An additional analysis of variance was performed on mean heart rate change per segment. The heart rate change score was computed by subtracting the mean heart rate for each segment from the mean heart rate for the 5-min adaptation period. A significant main effect was found for segments $[F(8,160)=4.71, p<.0001]$. In addition, there were significant interactions for Conditions by Segments $[F(8,160)=4.24, p<.001]$ and for Sex by Segments $[F(8,160)=2.04, p<.05]$. The segments effect reflected the fact that the most provocative dental segments elicited the highest heart rates. As with the verbal report data, no further analyses were performed on the Sex by Segments interaction. The Conditions by Segments interaction reflected the fact that there was a general increase in heart rate $(-.32$ to +1.2$)$ across segments in the heart increase condition and a general decrease in heart rate across segments in the heart decrease condition $(+3.4$ to -3.0$)$.

\section{DISCUSSION}

The contention that changes in perceived autonomic activity would be associated with concomitant changes in perceived affect in anxious subjects was supported, but only for males. Dentally anxious males who were exposed to decreasing nonveridical heart rate feedback responded to the dental presentation with less unpleasantness than dentally anxious males who were exposed to increasing nonveridical heart rate feedback. No comparable effect was found for females. Unfortunately, there are no other data on the interactive effects of nonveridical feedback and sex to which these findings can be directly compared. However, females tend to have a more intense negative reaction than males to dental treatment (Corah et al., 1978). As such, the affective reaction of dentally anxious females to the dental presentation may have been more resistant to modification than the affective reaction of dentally anxious males.

As expected, nonveridical heart rate feedback also modified actual heart rate. Dentally anxious subjects exposed to decreasing nonveridical heart rate feedback responded to the presentation with a general decrease in actual heart rate over segments. In contrast, dentally anxious subjects exposed to increasing nonveridical heart rate feedback responded to the dental presentation with a general increase in actual heart rate over segments. These findings disconfirm Valins' (1966) conclusion that autonomic activity is unaffected by nonveridical feedback. However, although the Conditions by Segments interaction was statistically significant, segment changes were relatively small. Also, in contrast to the unpleasantness ratings, heart rate was unaffected by sex. Thus, the changes in heart rate probably did not mediate the changes in perceived affect. Rather, the most likely possibility is that the nonveridical feedback was appraised cognitively as a component of an affective reaction to the dental presentation. In support of this possibility, nonveridical feed- back has been found to influence the cognitive appraisal of attributions (Nisbett \& Valins, 1972), persuasions (Hendrick, Giesen, \& Borden, 1975), response thresholds (White \& Wilkins, 1973), and fear communications (Harris \& Jellison, 1971).

The effects of nonveridical feedback on perceived affect found in this study parallel the previously reported effects of increasing and decreasing veridical heart rate feedback (e.g., Sirota et al., 1974, 1976). Thus, the mediator of the effects of veridical feedback on perceived affect may have been the perception of heart rate change rather than actual heart rate change. Lazarus (1975), in an elaboration of his cognitively oriented theory of emotion, highlighted the cue potential of physiological arousal during the cognitive appraisal of emotional stimuli. The data from this study indicate that Lazarus' view perhaps could be amended in the following manner. For some individuals, the cognitive appraisal of physiological cues could affect emotional attributions even if the cues do not necessarily reflect significant changes in actual physiological activity. This might be particularly true for high-anxious individuals who exaggerate internal cues. To the extent that this possibility is supported in future studies, the attenuation of arousal cognitions may be an alternative to the large number of techniques that are used to modify the physiological concomitants of stress.

\section{REFERENCES}

Corah, N. L. Development of a dental anxiety scale. Journal of Dental Research, 1969, 48, 596.

Corah, N. L., Gale, E. M., \& Illig, S. J. Assessment of a dental anxiety scale. Journal of the American Dental Association, 1978, 97, 816-819.

Corah, N. L., Gale, E. N., \& Illig, S. J. Psychological stress reduction during dental procedures. Journal of Dental Research, 1979, 58, 1347-1351.

Gatchel, R. J., \& Proctor, J. D. Effectiveness of voluntary heart rate control in reducing speech anxiety. Journal of Consulting and Clinical Psychology, 1976, 44, 381-389.

Goldstein, M. J., \& Palmen, J. O. The experience of anxiety: A casebook. Oxford: Oxford University Press, 1975.

Harris, V. A., \& Jellison, J. M. Fear arousing communications, false physiological feedback, and the acceptance of recommendations. Journal of Experimental Social Psychology, 1971, 7, 269-279.

Hendrick, C., Giesen, M., \& Borden, R. False physiological feedback and persuasion: Effect of fear arousal vs. fear reduction on attitude change. Journal of Personality, 1975, 43, 196-214.

Hirschman, R. Cross modal effects of anticipatory bogus heart rate feedback in a negative emotional context. Journal of Personality and Social Psychology, 1975, 31, 13-19.

Hirschman, R., \& Clark, M. Bogus physiological feedback. In J. T. Cacioppo \& R. E. Petty (Eds.), Social psychophysiology: $A$ sourcebook. New York: Guilford Press, in press.

Hirschman, R., \& Hawk, G. Emotional responsivity to nonveridical heart rate feedback as a function of anxiety. Journal of Research in Personality, 1978, 12, 235-242.

Hirschman, R., Revland, P., Hawk, G., \& Young, D. Effects of dental anxiety and phase of treatment on discomfort during dental simulation. Journal of Dental Research, 1980, 59, 1064.

Hirschman, R., Young, D., \& Nelson, C. Physiologically based techniques for stress reduction. In B. D. Ingersoll \& W. R. McCutcheon (Eds.), Clinical research in behavioral dentistry. Morgantown: West Virginia University Foundation, 1979.

Kazdin, A. E., \& WilcoxıN, L. A. Systematic desensitization and nonspecific treatment effects: A methodological evaluation. Psychological Bulletin, 1976, 83, 729-758.

LACEY, B. C., \& LACEY, J. I. Two-way communication between the heart and the brain. Significance of time within the cardiac cycle. American Psychologist, 1978, 33, 99-113. 
LAzARUS, R. A cognitively oriented psychologist looks at biofeedback. American Psychologist, 1975, 30, 553-561.

Myers, J. L. Fundamentals of experimental design. Boston: Allyn \& Bacon, 1979.

Nisbett, R. E., \& Valins, S. Perceiving the causes of one's own behavior. In E. E. Jones, D. E. Kanouse, H. H. Kelley, R. E. Nisbett, S. Valins, \& B. Weiner (Eds.), Attribution: Perceiving the causes of behavior. Morristown, N.J: General Learning Press, 1972.

Oliver, C., \& Hirschman, R. Voluntary heart rate control and perceived affect. Journal of Dental Research, 1982, 61, 8-10.

Sirota, A. D., Schwartz, G. E., \& Shapiro, D. Voluntary control of human heart rate: Effect on reaction to aversive stimulation. Journal of Abnormal Psychology, 1974, 83, 261267.

Sirota, A. D., Schwartz, G. E., \& Shapiro, D. Voluntary control of human heart rate: Effect on reaction to aversive stimulation. A replication and extension. Journal of Abnormal Psychology, 1976, 85, 473-477.
VAlins, S. Cognitive effects of false heart rate feedback. Journal of Personality and Social Psychology, 1966, 4, 400-408.

VALINS, S. Emotionality and information concerning internal reactions. Journal of Personality and Social Psychology, 1967, 6, 458-463.

White, M. D., \& Wilkins, W. Bogus physiological feedback and response thresholds of repressors and sensitizers. Journal of Research in Personality, 1973, 7, 78-87.

\section{NOTES}

1. Typically, in studies of nonveridical autonomic feedback, subjects are told that the feedback is genuine, but in fact it is prerecorded to reflect increases and decreases in autonomic activity.

2. Myers (1979) provides a rationale for doing post hoc comparisons subsequent to an $\mathrm{F}$ test with a $\mathrm{p}>.05$.

(Received for publication October 18, 1982.) 